\title{
On the dynamics emerging from pandemics and infodemics
}

\author{
Stephan Leitner
}

\begin{abstract}
This position paper discusses emerging behavioral, social, and economic dynamics related to the COVID-19 pandemic and puts particular emphasis on two emerging issues: First, delayed effects (or second strikes) of pandemics caused by dread risk effects are discussed whereby two factors which might influence the existence of such effects are identified, namely the accessibility of (mis-)information and the effects of policy decisions on adaptive behavior. Second, the issue of individual preparedness to hazardous events is discussed. As events such as the COVID-19 pandemic unfolds complex behavioral patterns which are hard to predict, sophisticated models which account for behavioral, social, and economic dynamics are required to assess the effectivity and efficiency of decision-making.
\end{abstract}

Keywords COVID-19 - delayed effects of pandemics · individual preparedness · policy making $\cdot$ adaptive society $\cdot$ social dynamics

\section{Emergent dynamics related to the COVID-19 pandemic}

The COVID-19 pandemic poses extreme and severe challenges to the society: There is a dramatic loss of lives worldwide, we experience and also expect for the future a multiplicity of challenges for economic systems, individuals are confronted with new and often very demanding situations, and public and private institutions are challenged to decide upon draconian measures under high time-pressure (Johns Hopkins University of Medicine 2020; Atkeson 2020; Xiang et al. 2020).

This paper discusses emergent issues which appear to become particularly relevant in the context of the COVID-19 pandemic: Section 2 focuses on delayed effects of pandemics and Section 3 discusses adaptive societies and preparedness in the context of hazardous events. The understanding of the dynamics which unfold during and

Stephan Leitner

University of Klagenfurt

Universitätsstraße 65-67

9020 Klagenfurt, Austria

E-mail: stephan.leitner@aau.at 
in the direct aftermath of a pandemic are key to effective and efficient management decisions. In additon, the insights into the dynamics of pandemics and infodemics ${ }^{1}$ can be employed for the good of the society in a long-term perspective as they might help minimize unwanted (and often delayed) effects.

\section{Delayed effects and their consequences for economic and social systems}

The temporal profile of hazardous events significantly affects how the related risks are perceived: Individuals are more averse to events in which a large number of people are harmed or killed in a short period in time, compared to events which have similar consequences but span over a longer time-period (Slovic 1987; Bodemer et al. 2013; Ayton et al. 2019). The COVID-19 pandemic, a low-probability and highconsequence event, is of the former type; individuals are very likely to perceive it as a dread risk (Gerhold 2020). This perception is likely to affect individual behavior, which might unfold rather complex dynamics: Gigerenzer (2004), for example, shows that such dread risks affect individual decision-making behavior not just in the short but also in the long run. For the aftermath of the $9 / 11$ attacks he finds that perception of the terrorist attack has caused a change in individual transport behavior and, in consequence, has led to an increase in traffic fatalities beyond what would have been expected without the change in individual behavior. It is likely that similar behavioral patterns will emerge in the aftermath of the COVID-19 pandemic.

These effects are likely to be shaped by two factors: The individual mind and structure of the environment (Gaissmaier and Gigerenzer 2012; Simon 1990). The former is affected by the perception of the COVID-19 pandemic as a dread risk with changes in behavioral patterns lurking (Gigerenzer 2004). The latter also affects individual behavior as it determines the boundaries for adaptivity (Simon 1990). The structure of the environment is, amongst others, shaped by policy decisions. These two influencing factors are discussed in the following subsections.

\subsection{The role of accessibility of (mis-)information}

Risks are made up of a multiplicity of qualitative and subjective attributes (Jenkin 2006; Slovic et al. 1981; Xu et al. 2020). ${ }^{2}$ However, risk-perception is also a sociocultural phenomenon: It is affected by the structure of networks between individuals (e.g., social networks, organizations) and the resulting world views (Gore et al. 2009; Sjöberg 2000; Marris et al. 1998). How individuals perceive risks is crucially affected by the information accessible to them (Huurne and Gutteling 2008), whereby accessibility of information and resulting opinions about factors influencing risk-perception

\footnotetext{
1 A infodemic is referred to as the rapid diffusion of misinformation that accompanies a pandemic (Zarocostas 2020; Vaezi and Javanmard 2020).

2 This is particularly true for non-experts, one common explanation is that experts put more emphasis on probabilities of harm or injury (Sjöberg 1999a). For further discussions related to factors driving differences in risk-perception between experts and non-experts and factors affecting individual risk-assessment see Sjöberg (1999b) and Bodemer et al. (2013), respectively.
} 
are often shaped by one's networks (Burt 1987; Scherer and Cho 2003; Grimm and Mengel 2020). ${ }^{3}$

Phenomena such as the infodemic, which accompanies the current pandemic, adds complexity to the the current situation: There is a chance that mis-information leads to unwanted effects in individual behavior so that the speed at which the virus spreads increases: Cinelli et al. (2020) argue that rumors about lockdowns in northern Italy led to overcrowded trains and airports, which, in consequence, increased the speed at which the virus spreads. Besides direct effects on behavior there might be indirect and delayed effects of an infodemic, as the spread of mis-information might increase the perception of the COVID-19 pandemic as a dread risk (Zarocostas 2020). It is, thus, plausible to assume that there are non-trivial interactions among behavioral implications induced by the COVID-19 pandemic and the accompanying infodemic which might result in complex dynamics: If not understood properly, mutually reinforcing dynamics with unprecedented consequences might unfold. These dynamics might be even reinforced by the algorithms employed by information platforms, which are usually designed to respond to the individual information-seeking behavior (Budak et al. 2016). It is, therefore, of ultimate importance to understand how people select information sources during hazardous events and how information dynamics interfere with risk perception and behavioral dynamics (Cinelli et al. 2020; Sharot and Sunstein 2020).

\subsection{The role of policy-making}

The structure of the environment is the second driving force behind delayed effects of the COVID-19 pandemic which is discussed in this paper as, following Simon (1990), it defines the limits of the adaptation. Gaissmaier and Gigerenzer (2012), for example, regard the availability of driving opportunities as a main factor that contributed to the change in behavioral patterns ${ }^{4}$ in the aftermath of the $9 / 11$ attacks which led to more fatalities than would have been expected without the change in behavior (see also Gigerenzer 2004). Similarly, López-Rousseau (2005) analyzed traffic patterns in the aftermath of terrorist train attacks in Spain in 2011: They observed that train travel had decreased in the months following the attacks, the amount of other traffic, however, had not increased. ${ }^{5}$ Aside from cultural reasons, López-Rousseau (2005) traces the differences back to political decisions and social factors: While the boundaries for individual adaptation after the $9 / 11$ attacks were set by shutting down all flight traffic, social factors caused a significant increase in train traffic on the days after the attack in Spain as demonstrations related to the attacks were organized across the country.

Thus, in the aftermath of hazardous events the environment appears to be a main factor to affect (and to set the boundaries for) the adaptation of individual behav-

\footnotetext{
3 For an extensive review of factors influencing information access see McCreadie and Rice (1999a) and McCreadie and Rice (1999b).

4 In terms of a shift from flying to driving (Gigerenzer 2004).

5 López-Rousseau (2005) argues that Spaniards might increased carpooling, decided to travel by bus or might have reduced travel alltogether.
} 
ior, whereby it appears to be shaped, amongst others, by policy decisions. ${ }^{6}$ This is why policy-makers would be well advised to consider the dynamics resulting from the interaction of decisions related to the aftermath of the COVID-19 pandemic with processes of individual adaptation in their policy decisions. Currently, there is a multiplicity of (often draconic) measures taken by different governments which are decided upon under time pressure and under limited information: It is, therefore, likely that policy-makers are not fully aware of the impact of their decisions (Elsenbroich and Badham 2020). This might be explained by the fact that the models currently employed hardly consider the full range of social and behavioral complexity (Squazzoni et al. 2020): They are well-suited for short-term policy-making which aims at reducing the speed at which the virus spreads. In order to provide proper policy advice for long-term decisions, however, extended models need to be developed in order to avoid poorly conceived policies which strike back through delayed behavioral effects.

\section{Preparedness and adaptive societies}

The second emerging topic discussed in this paper covers issues related to the preparedness of societies. ${ }^{7}$ This is an issue of ultimate interest: Oppenheim et al. (2019), for example, highlight that despite significant investment, many countries are not able to manage virus outbreaks. Preparedness, however, is not just a necessary feature at the macroscopic level but also needs to be analyzed at the level of the individual (Käser et al. 2019). There exist strong interrelations between the two levels: Lim et al. (2013), for example, found that institutional preparedness to disasters is positively affected by the individual preparedness of supervisors, while individual preparedness, amongst others, appears to be driven by the a person's experience with similar situations, the preparedness of colleagues and the family, and training. In order to increase the preparedness of a society, a multiplicity of issues has to be considered, such as communication and coordination infrastructure, health-care infrastructure, logistics to name but a few (Madad et al. 2020; Oppenheim et al. 2019; Gupta et al. 2018). However, soft factors which influence behavior at the individual level, such as strategies for information retrieval, also need to be taken into account (Misuraca et al. 2018).

Issues related to preparedness can be analyzed through the lens of complexity science: Societies are regarded as adaptive systems which consist of multiple human decision-makers and self-organization refers to a process in which the society, for example, creates an order or a structure and assigns roles, tasks or capabilities to be acquired by their members (Odum 1988; Di Marzo Serugendo et al. 2005). What appears to be particularly interesting in this context is how societies can be guided in their process of self-organization so that their resilience increases. There is enormous progress in the fields of engineering and information technology related to complex

\footnotetext{
6 There are, of course, other factors which affect the adaptation of individual behavior such as personal attitudes and norms (Montano and Kasprzyk 2015).

7 Preparedness is related to the concept of resilient societies, i.e., societies which are able to cope with external stresses as a result of social, political, and/or environmental change (Adger 2000).
} 
adaptive systems, when it comes to the consideration of systems composed of humans, their complexity increases significantly (Karwowski 2012). This might be due to a multiplicity of factors related to human behavior and interactions among them, such as culture, attitudes, and cognitive abilities. Regarding preparedness with respect to hazardous events, the functioning of soft factors and their interrelations with human factors might be even more challenging to capture in models, as situations with less predictable and more complex patterns in individual behavior need to be covered (Poletti et al. 2009; Funk et al. 2009; Reluga 2010; Del Valle et al. 2005).

The development of sophisticated models of adaptive human systems which capture the dynamics related to pandemics - with a particular focus on the soft-facts related to resilience - appears to be highly relevant. Such models might prov to be particularly useful when used to evaluate means to guide societies toward selforganization in order to increase their resilience.

\section{Final remarks}

This paper highlights some issues which emerge from pandemics and accompanying infodemics: Delayed effects of pandemics and factors influencing these effects, and the preparedness of adaptive societies. Understanding the dynamics related to pandemics and infodemics is an indisputable precondition for efficient and effective decision-making. The discussion provided in this paper hopefully gives an impulse to action towards research related to hazardous events that puts more emphasis on the emerging behavioral, social, and economic dynamics.

\section{Conflict of interest}

The author declares that he has no conflict of interest.

\section{References}

Adger WN (2000) Social and ecological resilience: Are they related? Progress in Human Geography 24(3):347-364

Atkeson A (2020) What will be the economic impact of COVID-19 in the US? Rough estimates of disease scenarios. National Bureau of Economic Research Working Paper Series 26867:1-25

Ayton P, Murray S, Hampton JA (2019) Terrorism, dread risk and bicycle accidents. Judgment and Decision Making 14(3):280-287

Bodemer N, Ruggeri A, Galesic M (2013) When dread risks are more dreadful than continuous risks: Comparing cumulative population losses over time. PloS one 8(6):e66544

Budak C, Goel S, Rao JM (2016) Fair and balanced? Quantifying media bias through crowdsourced content analysis. Public Opinion Quarterly 80(S1):250-271

Burt RS (1987) Social contagion and innovation: Cohesion versus structural equivalence. American Journal of Sociology 92(6):1287-1335

Cinelli M, Quattrociocchi W, Galeazzi A, Valensise CM, Brugnoli E, Schmidt AL, Zola P, Zollo F, Scala A (2020) The covid-19 social media infodemic. arXiv preprint: 200305004

Del Valle S, Hethcote H, Hyman JM, Castillo-Chavez C (2005) Effects of behavioral changes in a smallpox attack model. Mathematical Biosciences 195(2):228-251 
Di Marzo Serugendo G, Gleizes MP, Karageorgos A (2005) Self-organization in multi-agent systems. Knowledge Engineering Review 20(2):165-189

Elsenbroich C, Badham J (2020) Focussing on our strengths. Review of Artificial Societies and Social Simulation URL https://rofasss.org/2020/04/12/focussing-on-our-strengths/

Funk S, Gilad E, Watkins C, Jansen VAA (2009) The spread of awareness and its impact on epidemic outbreaks. Proceedings of the National Academy of Sciences 106(16):6872-6877

Gaissmaier W, Gigerenzer G (2012) 9/11, Act II: A fine-grained analysis of regional variations in traffic fatalities in the aftermath of the terrorist attacks. Psychological science 23(12):1449-1454

Gerhold L (2020) COVID-19: Risk perception and Coping strategies. PsyArXiv URL doi:10.31234/osf.io/xmpk4

Gigerenzer G (2004) Dread risk, September 11, and fatal traffic accidents. Psychological Science 15(4):286-287

Gore ML, Wilson RS, Siemer WF, Wieczorek Hudenko H, Clarke CE, Sol Hart P, Maguire LA, Muter BA (2009) Application of risk concepts to wildlife management: Special issue introduction. Human Dimensions of Wildlife 14(5):301-313

Grimm V, Mengel F (2020) Experiments on belief formation in networks. Journal of the European Economic Association 18(1):49-82

Gupta V, Kraemer JD, Katz R, Jha AK, Kerry VB, Sane J, Ollgren J, Salminen MO (2018) Analysis of results from the joint external evaluation: Examining its strength and assessing for trends among participating countries. Journal of Global Health 8(2)

Huurne ET, Gutteling J (2008) Information needs and risk perception as predictors of risk information seeking. Journal of Risk Research 11(7):847-862

Jenkin CM (2006) Risk perception and terrorism: Applying the psychometric paradigm. Homeland Security Affairs 2(2):1-14

Johns Hopkins University of Medicine (2020) COVID-19 global cases. URL https://coronavirus.jhu.edu/map.html

Karwowski W (2012) A review of human factors challenges of complex adaptive systems: discovering and understanding chaos in human performance. Human Factors 54(6):983-995

Käser M, Maduz L, Prior T, Roth F (2019) Individual disaster preparedness: Explaining disaster-related information seeking and preparedness behavior in Switzerland. Tech. rep., ETH Zürich

Lim GH, Lim BL, Vasu A (2013) Survey of factors affecting health care workers' perception towards institutional and individual disaster preparedness. Prehospital and Disaster Medicine 28(4):353-358

López-Rousseau A (2005) Avoiding the death risk of avoiding a dread risk: The aftermath of March 11 in Spain. Psychological Science 16(6):426-428

Madad S, Moskovitz J, Boyce MR, Cagliuso NV, Katz R (2020) Ready or not, patients will present: Improving urban pandemic preparedness. Disaster Medicine and Public Health Preparedness pp 1-4

Marris C, Langford IH, O'riordan T (1998) A quantitative test of the cultural theory of risk perceptions: Comparison with the psychometric paradigm. Risk Analysis 18(5):635-647

McCreadie M, Rice RE (1999a) Trends in analyzing access to information. Part I: cross-disciplinary conceptualizations of access. Information Processing \& Management 35(1):45-76

McCreadie M, Rice RE (1999b) Trends in analyzing access to information. Part II. Unique and integrating conceptualizations. Information Processing \& Management 35(1):77-99

Misuraca G, Pasi G, Viscusi G (2018) Social innovation and resilience: Exploring the dynamics and impacts on the digital transformation of governance \& society. In: Proceedings of the 11th International Conference on Theory and Practice of Electronic Governance, pp 91-100

Montano DE, Kasprzyk D (2015) Theory of reasoned action, theory of planned behavior, and the integrated behavioral model. In: Glanz K, Rimer BK, Viswanath K (eds) Health Behavior: Theory, Research and Practice, 5th edn, Jossey-Bass, San Francisco, pp 95-124

Odum HT (1988) Self-organization, transformity, and information. Science 242(4882):1132-1139

Oppenheim B, Gallivan M, Madhav NK, Brown N, Serhiyenko V, Wolfe ND, Ayscue P (2019) Assessing global preparedness for the next pandemic: development and application of an Epidemic Preparedness Index. BMJ Global Health 4(1):e001157

Poletti P, Caprile B, Ajelli M, Pugliese A, Merler S (2009) Spontaneous behavioural changes in response to epidemics. Journal of Theoretical Biology 260(1):31-40

Reluga TC (2010) Game theory of social distancing in response to an epidemic. PLoS Computational Biology 6(5):e1000793

Scherer CW, Cho H (2003) A social network contagion theory of risk perception. Risk Analysis: An International Journal 23(2):261-267 
Sharot T, Sunstein CR (2020) How people decide what they want to know. Nature Human Behaviour 4:14-19

Simon HA (1990) Invariants of human behavior. Annual Review of Psychology 41(1):1-20

Sjöberg L (1999a) Consequences of perceived risk: Demand for mitigation. Journal of Risk Research 2(2):129-149

Sjöberg L (1999b) Risk perception by the public and by experts: A dilemma in risk management. Human Ecology Review pp 1-9

Sjöberg L (2000) Factors in risk perception. Risk Analysis 20(1):1-12

Slovic P (1987) Perception of risk. Science 236(4799):280-285

Slovic P, Fischhoff B, Lichtenstein S (1981) Rating the risks. In: Risk/benefit analysis in water resources planning and management, Springer, pp 193-217

Squazzoni F, Polhill JG, Edmonds B, Ahrweiler P, Antosz P, Scholz G, Borit M, Verhagen H, Giardini F, Gilbert N (2020) Computational models that matter during a global pandemic outbreak: A call to action. Journal of Artificial Societies and Social Simulation 23(2):1-10

Vaezi A, Javanmard SH (2020) Infodemic and risk communication in the era of CoV-19. Advanced Biomedical Research 9(1):10

Xiang YT, Yang Y, Li W, Zhang L, Zhang Q, Cheung T, Ng CH (2020) Timely mental health care for the 2019 novel coronavirus outbreak is urgently needed. The Lancet Psychiatry 7(3):228-229

Xu Z, Li J, Shan J, Zhang W (2020) Extending the Theory of Planned Behavior to understand residents' coping behaviors for reducing the health risks posed by haze pollution. Environment, Development and Sustainability pp 1-21

Zarocostas J (2020) How to fight an infodemic. The Lancet 395(10225):676 